\title{
The Role of Government towards a Circular Economy in the Construction Industry: A Systematic Literature Review
}

\author{
MKCS Wijewickrama*, Nicholas Chileshe, Raufdeen Rameezdeen, J Jorge Ochoa \\ University of South Australia, UniSA STEM, Scarce Resources and Circular Economy (ScaRCE), Adelaide, \\ Australia
}

\begin{abstract}
A circular economy (CE) model provides an opportunity for the construction industry (CI) to keep the end-of-life materials in a closed loop with their maximum value while advocating the reduction of significant waste generation and natural resource extraction for the built environment. While previous studies in different geographical regions have been individually carried out on investigating the government engagement in the $\mathrm{CE}$, no solitary study exists that holistically focus upon the role of government that steers the CI towards a CE. With this concern, the objectives of the current study are twofold. First, to investigate the roles through which the government contributes to implementing CE in the CI. Second, it outlines the potential research directions for future researchers to expand the domain under study. To achieve these objectives, a systematic literature review (SLR) was conducted based on the review protocol, Preferred Reporting Items for Systematic Reviews and Meta-Analyses (PRISMA). A total of 125 articles available in four search engines from 2002 to 2020 were incorporated for both descriptive and content analysis. Most articles (19) were published in the year 2019, and China is the dominant country for publishing most of the articles in the area under study. The study found that the government influences the CE in the CI by playing four significant roles: regulating, subsidizing, encouraging and informing. Herein, the government should play these four roles jointly with the amalgamation of government agencies, research institutions and nongovernment associations. The article concludes by outlining the future research priorities to advance the understanding in the domain under study. The value of the study is that it explores an overlooked area in the existing literature while providing a direction for the CI practitioners to understand the government role in paving the path to a CE.
\end{abstract}

Keywords: Built environment, Circular economy (CE), Construction industry (CI), Government, Preferred Reporting Items for Systematic Reviews and Meta-Analyses (PRISMA), Systematic literature review (SLR)

\section{Introduction}

The construction industry (CI) embraced a linear supply chain with the concept of "take, make, consume and dispose of" (Esa et al., 2017, p.1145). This traditional supply chain starts with the extraction of raw materials, which then processed into building materials and assembled into a structure in such a way that cannot be deconstructed. Consequently, bulks of waste produced at the end-of-life (EoL) of a structure have to be disposed of in landfills or incinerated, without reusing, recycling or remanufacturing. In contrast, over the last decade, the $\mathrm{CI}$ endeavoured in attaining the circular economy (CE) by embracing a circular supply chain with the intent of better management of scarce resources (Pomponi and Moncaster, 2017). In the circular supply chain, the building structures can deconstruct at the EoL, so the building materials and components could be reused while keeping them in a closed-loop (Hopkinson et al., 2020). Therefore, transforming from a linear to a circular supply chain advocates the CI to reduce bulks of virgin materials and generation of waste while steering the industry to achieve the foremost sustainability agenda (Esa et al., 2017).

The roots of the notion of the CE reached back many decades and advanced from many other concepts such as spaceman economy (Boulding, 1966), cradle-to-cradle (Stahel and Reday-Mulvey, 1981), and performance economy (Stahel, 2010). Since there is a need for synergizing the sustainability and built environment (Pomponi and Moncaster, 2017), contemporary researchers are keen on investigating CE in the CI. According to Benachio 
et al. (2020), the CE in the CI is "the use of practices, in all stages of the life cycle of a building, to keep the materials as long as possible in a closed-loop, to reduce the use of new natural resources in a construction project" (p.5). As per this definition, two aspects need to be considered when planning research around CE in the CI: life cycle stages of a construction project and circular economy practices (CEP) across these stages.

There are five stages in the circular supply chain of a building: project design, manufacture, construction, operations and EoL (Benachio et al., 2020). However, the author criticized that most of the previous studies about $\mathrm{CE}$ in the $\mathrm{CI}$ are framed around the reverse logistics supply chain (RLSC), representing one stage of the entire building life cycle. Nasir et al. (2017) argued that CEP are mostly attainable during the RLSC of a building because the EoL stage enables the salvageable waste to re-enter the forward supply chain after subjecting to reprocessing. Figure 1 shows the CEP of each building life cycle stage in the CI. Although these practices were separated among life cycle stages, this separation is not absolute (Adams et al., 2017; Benachio et al., 2020). Accordingly, some of the practices could be overlapped and can implement in different life cycle stages. However, they are listed in the most relevant stage for the easy scrutiny of this study. All these practices are essential for CE (Adams et al., 2017), and primarily the government's contribution plays a decisive role in implementing them successfully in the CI (Akinade et al., 2020).

The government has the statutory capacity to lead sustainable development in the built environment (Ghisellini et al., 2016). Correspondingly, many previous studies pointed out that the government has a pivotal role in a meaningful transition towards the CE in the CI (Van Buren et al., 2016; Munaro et al., 2020). For instance, being a developing economy with slightly similar characteristics to developed nations, the Chinese government was prominent in planning a $\mathrm{CE}$ to pursue robust economic development while sustaining environmental sustainability (Munaro et al., 2020). The authors further explained that the Chinese government had recognized the importance of $\mathrm{CE}$ implementation to solve environmental degradation due to the upsurge in construction activities (Munaro et al., 2020). Furthermore, Van Buren et al. (2016) highlighted that the Dutch government, as a facilitator, provides support to speed up the transforming process to $\mathrm{CE}$ and remove any legislative bottlenecks for its implementation. Therefore, it is understandable that the government has a significant role in transforming CI from a traditional linear supply chain to a circular supply chain. Even though many previous studies separately pointed out the government involvement in CE in the CI (Van Buren et al., 2016; Akinade et al., 2020), no solitary study exist that holistically focus upon the role of government that steers the CI towards a CE. Given this knowledge gap, the motivation of conducting this systematic literature review (SLR) is to answer the research question: "what are the government roles in implementing CE in the CI?". This research question indicates that the study needs a broad qualitative approach. Therefore, the tool PICo (Population or Problem, Interest, Context), which is commonly used in qualitative reviews, was adopted to develop this research question (RMIT University, 2021). Accordingly, in this SLR, the population is the governments of different countries; the interest is implementing CE, and the context is the CI. 


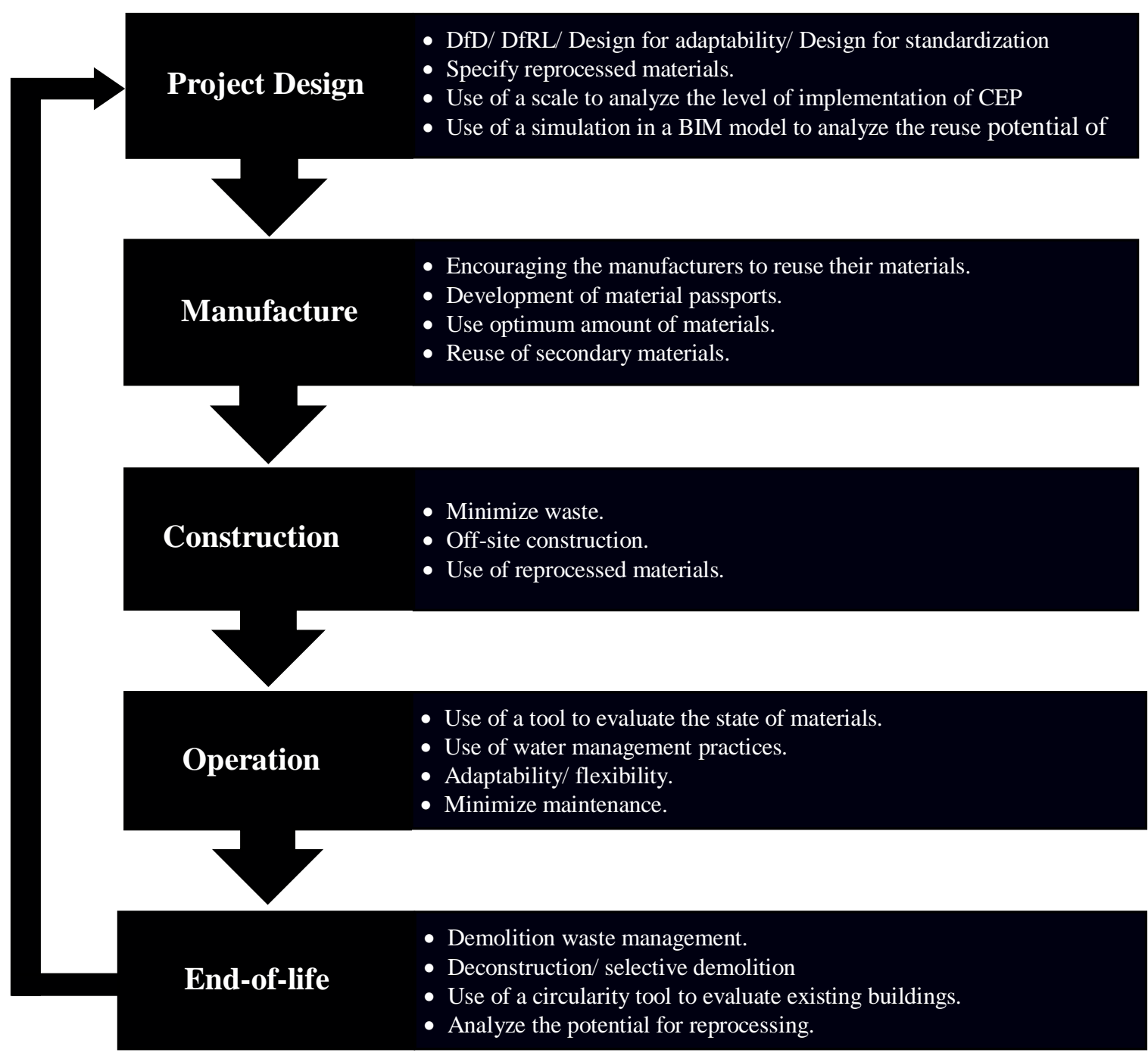

Figure 1. Circular economy practises across stages in the construction supply chain

(Adopted from Adams et al., 2017; Benachio et al., 2020)

With shedding light on this, the objectives of the current study are twofold: (i) to investigate the roles through which the government contributes to implementing $\mathrm{CE}$ in the $\mathrm{CI}$; and (ii) to outlines the potential research directions for future researchers to expand the domain under study. Drawing upon these objectives, the SLR aims to synthesize the body of literature to discern the government role in implementing CE in the CI. This study's original contribution is that it provides a blend of existing knowledge around government involvement in $\mathrm{CE}$ implementation that is not identifiable from reading separate individual articles. Additionally, it outlines the next research line that assists future researchers in diffusing the domain under study.

\section{Methodology}

According to Tranfield et al. (2003), a SLR differs from a traditional narrative review because the former is adopting a replicable, scientific and transparent process. Accordingly, the review was undertaken based on the review protocol, Preferred Reporting Items for Systematic Reviews and Meta-Analyses (PRISMA), which provides substantial transparency for the selection process of articles and improve the reporting quality of the systematic review (Moher et al., 2009). 
The article search for the review was done using one search string connecting keywords with Boolean connectors as of "Reverse Logistics" OR "Reverse Supply Chain" OR "Circular Econom*" AND "Construction industry". The keywords were searched in four electronic search systems: Google Scholar, Web of Science, Scopus and ScienceDirect. The reason for using several search systems is to gather a rich repository of articles without permitting any bias in selection (Ali et al., 2017). Furthermore, all these search systems are permitted to access multidisciplinary articles and readily available in academic institutions. Initially, the article was started to search in September 2020 and was repeated in January 2021. Jia et al. (2020), from their SLR showed that the studies around CE in the CI initially began to evolve in 2002. Therefore, the search period for the current study was set from 2002-2020. The inclusion and exclusion criteria of the review are summarized in Table 1.

Table 1. Inclusion and exclusion criteria of the review

\begin{tabular}{|c|c|c|c|c|}
\hline Criteria & Exclusions & $\begin{array}{l}\text { No. of } \\
\text { articles }\end{array}$ & Inclusions & $\begin{array}{l}\text { No. of } \\
\text { articles }\end{array}$ \\
\hline Keywords & \multicolumn{4}{|c|}{$\begin{array}{l}\text { "Reverse Logistics" OR "Reverse Supply Chain" OR "Circular Econom*" AND } \\
\text { "Construction industry" }\end{array}$} \\
\hline Timespan & \multicolumn{4}{|l|}{$2002-2020$} \\
\hline Search systems & \multicolumn{4}{|c|}{ Google Scholar, Web of Science, Scopus and ScienceDirect } \\
\hline Article type & $\begin{array}{l}\text { Literature reviews, B.Sc. / M.Sc. /PhD } \\
\text { thesis, reports, books, book chapters, } \\
\text { editorials }\end{array}$ & 40 & $\begin{array}{l}\text { Journal articles, } \\
\text { Conference papers }\end{array}$ & 115 \\
\hline Language & All other languages except English & 5 & English & 115 \\
\hline \multirow{4}{*}{ Others } & $\begin{array}{l}\text { Irrelevant to the research area (e.g. } \\
\text { supply chain management, blockchain } \\
\text { technology, manufacturing industry) }\end{array}$ & 117 & via cross-referencing & 10 \\
\hline & Not relevant to the current topic & 43 & & \\
\hline & Not accessible & 16 & & \\
\hline & Duplicates & 24 & & \\
\hline
\end{tabular}

Figure 2 presents the refinement process of the study. The initial search found 360 articles and subjected them to subsequent exhaustive refinement. As the first step, each of these articles' titles and abstracts was examined to confirm their relevance for the current study. Herein, the peer-reviewed journal articles and conference papers published in English were incorporated, and the articles with unrelated themes were excluded. Subsequently, 174 articles were left for the following screening. Finally, 184 articles were fully read, which also include 10 additional articles that were determined as applicable for the current review via cross-referencing. During this exhaustive examination, 43 articles were excluded because they were not applicable to the current review's purpose, and 16 articles were inaccessible. Finally, 125 articles remained for the current review. 

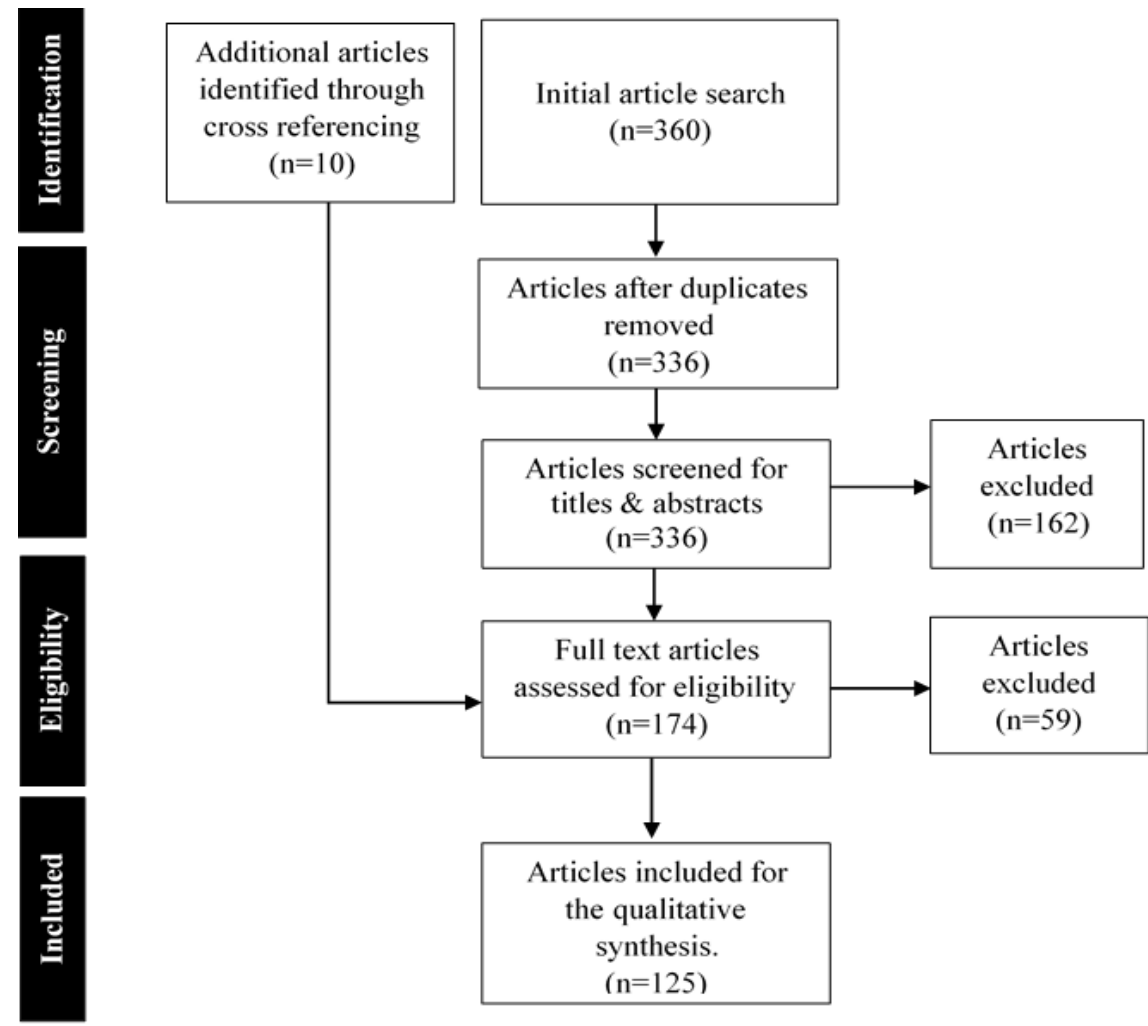

Figure 2. Refinement process based on PRISMA guideline

(Adapted from Moher et al., 2009)

The selected articles were first subjected to the descriptive analysis, and this offers a robust foundation for the subsequent content analysis (Prajapati et al., 2019). Under descriptive analysis, the bibliographic details of the refined articles were tabulated based on their publication year and location of data collection. After that, the content analysis was done, which helps to make various interpretations on the comprehension of the paper (Seuring and Müller, 2008). The authors further stated that the structural dimensions that form the content analysis's major themes could be raised either deductively or inductively. In the current review, all these structural dimensions were derived by following an inductive approach. There is a risk of emerging a potential bias in the content analysis (Seuring and Müller, 2008). To minimize this, all four researchers were contributed to searching for and analyzing the findings. Herein, the first researcher initially reviewed and analyzed all the sorted articles, and then, the remaining researchers refined, revised and finalized the findings. This approach enhanced the qualitative findings reliability and was also followed in the SLR by Prajapati et al. (2019).

\section{Results of the Descriptive Analysis}

Figure 3 presents the annual distribution of the articles published during 2002-2020. It shows a sporadic trend in the publications increasing from seven to 16 after 2016. The greatest number of articles (19) was published in the year 2019. It is noteworthy that the majority of the articles were published during the last four years (2017-2020), which accounts for 53\% of the total articles. The growing number of articles reflect the enhanced interest of researchers in the area under study. 


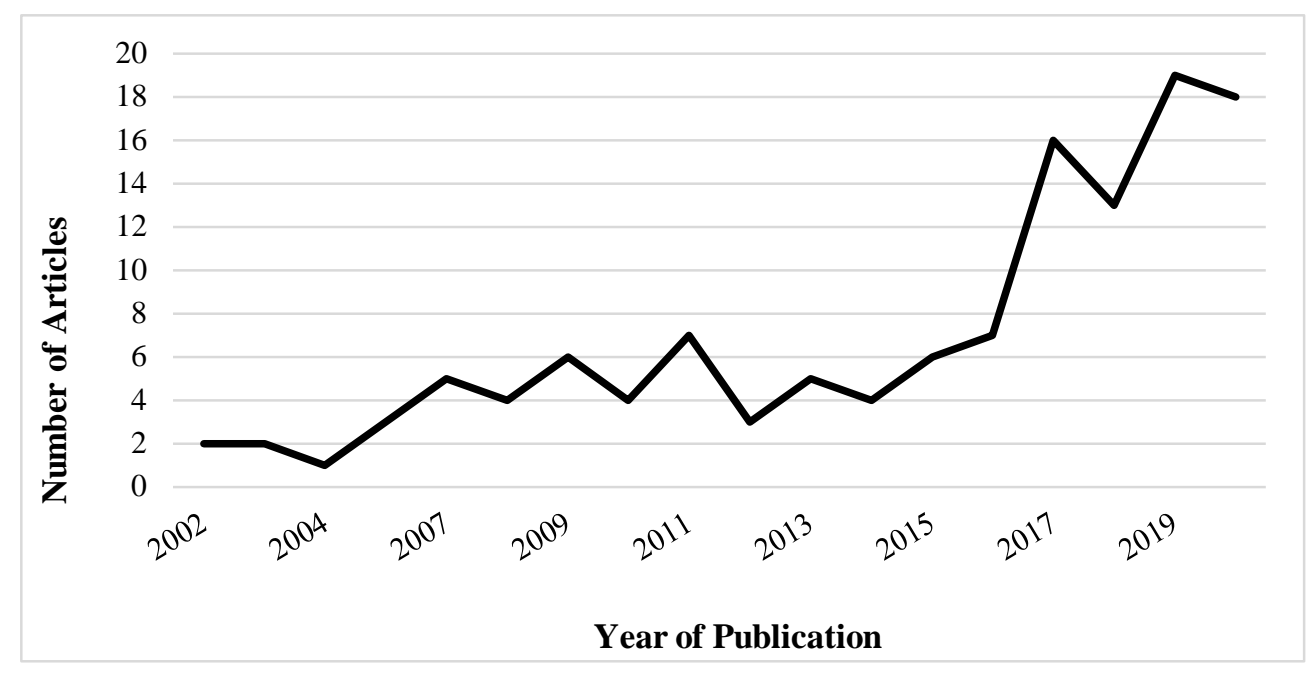

Figure 3. Year-wise publications from 2002 to 2020

Figure 4 outlines the most significant countries that contributed to publishing most articles in the study domain at least with 3 articles. A greater number (23) of the articles were originated from China, followed by Australia and UK, with 13 each. Noteworthily, developing countries are almost equally contributing as developed countries in publishing the article on the research area.
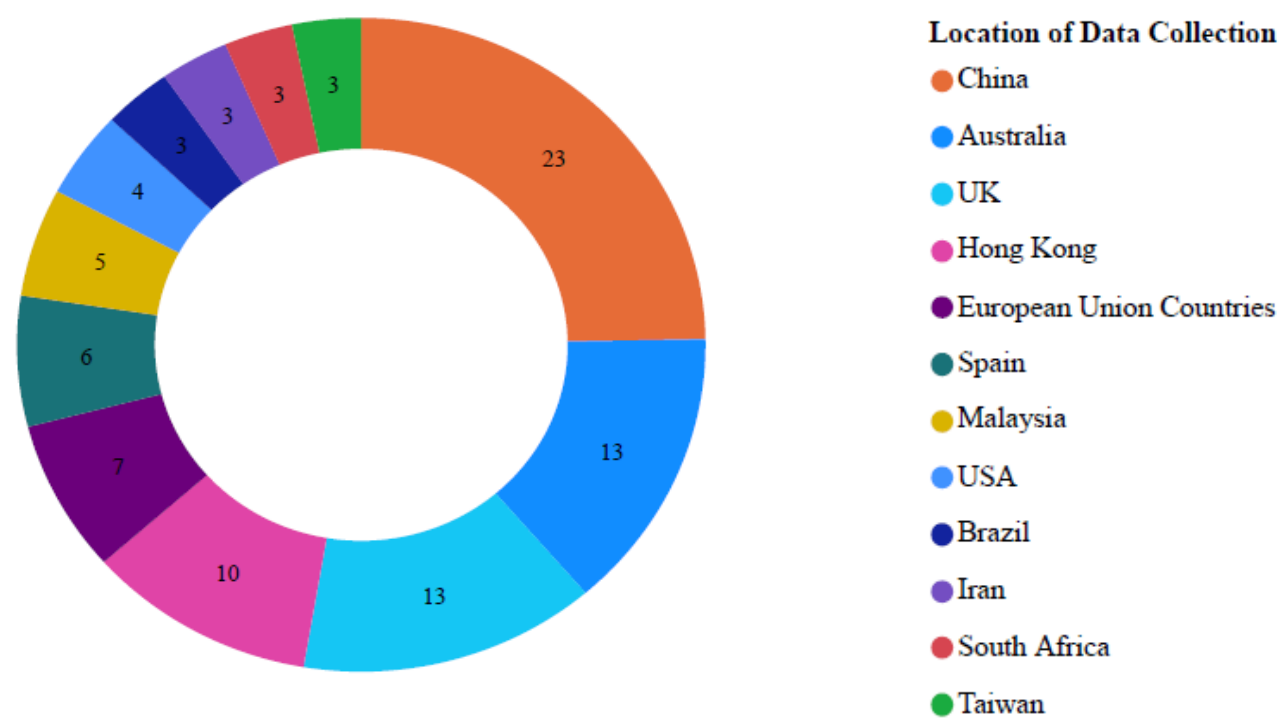

Figure 4. Geographical distribution of refined articles based on the location of data collection

\section{Results of the Content Analysis}

This section presents the content analysis findings in line with the overall perspective of literature on the government's crucial role in implementing CE through drivers associated with its laws, policies, tax levies, and strict governance. The level of contribution coming from the government for CE is vital for promoting CEP (Benachio et al., 2020). The study found four roles through which the government contribute to the $\mathrm{CE}$ implementation in the CI: regulating, subsidizing, encouraging and informing. The following sections explain each of these roles comprehensively. 


\section{Regulating}

Under the role of regulating, the government enforce laws and legislation and regulate landfill levy and related policies to implement $\mathrm{CE}$ in the $\mathrm{CI}$. Each of these sub-roles broadly explains as follows.

\section{Enforcing laws and legislation}

Through laws and legislation, the government produces its national/state plan, which constitutes goals, targets and vision to transform from linear to circular supply chain (Rodríguez et al., 2015; Mahpour, 2018). For instance, in Spain, the national legislation includes the Royal Decree, the national construction and demolition waste (CDW) management plan and Act related to CDW management (Rodríguez et al., 2015). This legislation describes all the actors' responsibilities in the construction supply chain to manage CDW while reducing the waste destined at landfills. The Royal Decree mandates to development of a waste management model, which includes a waste management report developed by architects and engineers during the design phase and a waste management plan developed by contractors during each construction project's planning phase. Furthermore, the Act mandates builders to provide the local authority with an estimate of waste to be generated and measures to sort and manage the corresponding amount of waste (Rodriguez et al., 2007).

The construction material law in Japan aims to upsurge the recycling and reuse of construction materials (Tam, 2009). This law forces industry practitioners to implement effective waste management procedures such as onsite sorting, reusing and recycling. Due to these regulatory requirements, Japanese construction organizations have in-house waste management teams to implement effective waste management processes within construction projects.

\section{Regulating landfill levy and corresponding policies}

The uncontrollable generation of construction waste has acquired the landfill carrying capacities in many congested nations, such as China and Hong Kong (Yu et al., 2013). Thus, there is a grave necessity for diverting waste from landfills and promoting CEP, such as reusing and recycling. This could be achieved by enforcing landfill ban policies for specific materials (Calvo et al., 2014). For instance, the CDW that contains more than $20 \%$ inert materials is restricted to dumped in landfills in Hong Kong. Besides, the landfill levy is also a crucial policy imposed by the government to force the $\mathrm{CI}$ to adopt CEP and discourage landfilling (Li et al., 2018). The low CDW landfill levy indirectly persuades the construction practitioners and EoL actors to discard the untreated waste without recycling or reusing it easily (Huang et al., 2018). On the other hand, extremely high disposal charges also lead to more illegal dumping or waste diversions to the low fee areas (Yuan, 2017; Huang et al., 2018). For instance, the unlawful CDW dumping rate increased by four times in Hong Kong during a year after introducing a very high waste landfill levy in 2005 (Yu et al., 2013). An optimum landfill levy cannot be decided by referring to other regions or countries due to deviations in social, cultural and economic status (Li et al., 2018). Therefore, each country's government has a role in determining the optimum landfill levy in the way it is appropriately customized to the region's socio-economic condition (Li et al., 2018).

\section{Subsidizing}

The government provides financial subsidies for CEP and develop the needed infrastructure to implement CE in the CI. Each of these sub-roles could be explained in detail as follows.

\section{Providing financial subsidies for circular economy practices}

According to Chang and Hsieh (2019), the lack of government incentives is a key challenge for the CE implementation in the CI. Unlike the government, which most consider the environmental benefits of waste 
management, the practitioners in the $\mathrm{CI}$ always stimulated by the financial benefits of waste management (Ajayi and Oyedele, 2017). For instance, the governments provide some incentives and prompt rewards to contractors to encourage source reduction, reusing and recycling on-site construction waste in Malaysia (Begum et al., 2007) and Australia (Chileshe et al., 2015). The UK government provides tax exemptions and incentives for good waste management businesses (Ajayi and Oyedele, 2017). Moreover, the government in Hong Kong inspires the recyclers to recycle different types of CDW by offering land and financial incentives (Hao et al., 2008). All the $\mathrm{CI}$ actors are induced to embrace CEP to receive these government subsidies, and this will eventually promote the CE implementation in the CI.

\section{Development of needed infrastructure}

The availability of innovative infrastructure plays a paramount role in waste management processes (Banias $e t$ al., 2010). However, several authors pointed out that the unavailability of adequate and effective infrastructure facilities hinders CDW management in many countries in the world (Calvo et al., 2014; Esa et al., 2019). For instance, in Hong Kong, the long-distance between construction and demolition sites and the recycling plant prevents contractors from transferring salvageable materials to recycling plants due to extremely high transportation costs and traffic congestion (Tam and Tam, 2006). The CDW management facilities should be set up at hot-spot locations with maximum local acceptance, financial viability and a minimum environmental burden (Banias et al., 2010; Esa et al., 2017). Correspondingly, in most European countries, new recycling plants have been set up at desirable locations with government subsidies (Schamne and Nagalli, 2018). Noteworthily, the government is barely subsidizing infrastructure facilities for CDW management in some countries like Spain (Rodríguez et al., 2015).

\section{Encouraging}

The government is playing the role of encouraging the parties in the CI to embrace CEP in their everyday business routines. According to Hao et al. (2007), the Hong Kong government has introduced an environmental management system (EMS) to ensure that the CEP are embedded in the construction management businesses' processes. This EMS includes a standard framework of five stages: environmental policies, planning, implementation and operations, checking and corrective action, measurement review and improvement (Hao et al., 2007). The authors further underpinned that this system is acting as a vehicle for construction organizations to develop CEP. By introducing the EMS, the Hong Kong government encourages the accumulation of total commitment and cooperation of all the parties involved in the circular supply chain to follow CEP; including developers, designers, manufacturers, contractors, and the actors in the end-of-life stage (Hao et al., 2007).

Since the clients and designers are having less confidence in incorporating the reprocessed products, Tam (2009) accentuated that the government should involve and manage the initial control of recycling centres to expand the industry's awareness towards the reprocessed products. For instance, Zhao et al. (2011) mentioned that after operating for several years, the Chinese government's recycling centres would be bestowal to the private investors and encourage them to invest more in recycling centres. By doing this, the Chinese government encourages the private sector to invest more in the recycling sectors.

\section{Informing}

Many previous studies pointed out that adequate knowledge, skills, awareness, and experience are important to stimulate various parties' willingness to follow CEP (Chileshe et al., 2015; 2016). However, the review of the literature revealed that the majority of parties in the circular supply chain lack this essential knowledge, skills and experience (Adams et al., 2017; Ali, 2019). Herein, the government has a critical role in making the knowledge accessible and understandable to parties. Wu et al. (2016) found that government and its associated agencies play 
an important role in educating, informing and guiding the Chinese contractors to exhibit excellent CDW management behaviour. Begum et al. (2006) stated that the CI Development Board (CIDB) in Malaysia has an important role in disseminating the information for designers, developers, contractors, sub-contractors and other stakeholders in the CI about the adverse environmental impacts of waste and cost savings from reusing and recycling waste materials. Similarly, Begum et al. (2007) expounded that the same government agency could conduct some education and training programmes and construction campaigns to support the Malaysian construction practitioners in planning and adopting waste management during design and construction stages. In Spain, the Ministry of Environment Rural and Marine used media to raise public awareness of the need to reduce the CDW treatment issues (Calvo et al., 2014). Furthermore, in Australia, the construction project members are encouraged to participate in government agencies' training programs under the state governments' instructions (Tam, 2009). These staff members then disseminate the knowledge gained from training with other staff members through tailored internal training sessions.

\section{Discussion}

The descriptive analysis of the study outlined that there is a growing interest in publishing on the domain under study, primarily in the last four years. Noteworthily, the percentage of articles published in the last four years is nearly half of the total number of articles refined for the current review. The recent SLR by Benachio et al. (2020) on $\mathrm{CE}$ in the $\mathrm{CI}$ also reflected a similar trend in articles. This upsurge in the number of articles indicates that contemporary researchers are more concerned about promoting sustainable approaches in the CI. The descriptive results also demonstrate that China is the most predominant country in publishing most articles. China is a globally domineering country in CE implementation mainly due to its political impetus (Munaro et al., 2020). Therefore, refining most articles from China is admissible. Additionally, the developed countries like Australia and UK are also contributing significantly to publications on the topic.

The transformation from the linear to the circular supply chain has paved the path for the CI to solve most of its sustainability issues (Benachio et al., 2020). The CI could not self-steer this transformation, and thus, it needs an impetus from an external driver. The government has the utmost positive impact on the CE implementation in supply chains, irrespective of the industry, through enforcing laws and policies, risk reduction via tax levies and strict governance (Govindan and Hasanagic, 2018). Further intensifying these findings, the current study established that the government is playing a pivotal role in the CE implementation in the CI through playing roles of "regulating", "subsidizing", "encouraging", and "informing". Similar to the findings of previous SLRs on RLSC by Wijewickrama et al. (2020a; b; 2021), the current review also underpinned that the government formulate laws and legislation to provide a statutory framework for CE implementation in the CI. By developing infrastructure and providing financial grants, the government subsidizes the CI to embrace CEP. Furthermore, the government also encourages and informs the CI practitioners of the positive impacts of adopting CE.

Even though the government has a role in promoting $\mathrm{CE}$ in the $\mathrm{CI}$, the literature shows scant examples where the government is exclusively engaged from a real-life context. Therefore, many previous studies suggested many ways that the government could contribute to $\mathrm{CE}$ in the CI. For instance, as the regulator, the government could mandate contractors to use a particular portion of reprocessed products in public sector projects (Ajayi and Oyedele, 2017). The government also could provide financial subsidies to promote the usage of reprocessed products in the CI. In this regard, the government could impose a tax on virgin materials (Mália et al., 2013) and exert tax relief for manufacturers, suppliers and users of reprocessed products (Ajayi and Oyedele, 2017). Furthermore, the government could introduce a national quality labelling for reprocessed products and assign applicable government agencies to control the quality of reprocessed products before introducing those to the secondary market (Tam, 2009).

The current review found that the CE implementation is not a solitary effort of the $\mathrm{CI}$ and the government. Even though the government plays a central role, the government agencies, research institutions, and non-government 
associations should support the government and the CI to make the CE adoption a success, as in the case of China. The Chinese government has developed a collaborative and comprehensive operational framework for CE where all the relevant government agencies and other professional communities are bounded by specific laws and regulations (Zhu et al., 2018). According to Nunes et al. (2018), the universities and research institutions also play a role in CE implementation by conducting training sessions and research and developments (R\&D) under the government's auspices. For instance, the Chinese government and the universities have been devoted to deal with CDW management issues. As a result of this, the research around CDW management in China began to appear in most academic journals, and they provide influential knowledge for other countries to design their roadmap for CE implementation (Hao et al., 2010). Also, the non-government organizations, under the government influence, could contribute to CE implementation. As an example, Zanni et al. (2018) highlighted that U.S. Green Building Council, through their building rating system, seeks to optimize the use of virgin materials and promote reprocessing of components and materials in the CI. In summary, the current study reinforced that the government, as the key player in successful CE implementation, should regulate, subsidize, encourage, and inform the CI with the amalgamation of government agencies, academic institutions, and nongovernment organizations.

\section{Limitations and further research directions}

According to Snyder (2019), a well-organized literature review that constitutes an extensive research agenda makes a vital contribution to the area under the study. Correspondingly, the current review has few limitations and found some gaps in the extant literature, which could be addressed through future research. First, even though the review method is well-organized, the current study encompasses some limitations. This review only included peer-reviewed resources, excluding grey literature. However, Geissdoerfer et al. (2017) stated that the grey literature also could offer a significant knowledge contribution to the review. Thus, a future SLR is recommended to expand the findings by including grey literature around the area under study. Second, the current study found the role of government in CE implementation in the CI via a SLR. Since this is an important research area significantly overlooked in the existing literature, more empirical research is recommended to do, especially considering the current study's findings as to the basis. Third, the current study found that a collaborative effort of government, government agencies, research institutions and non-government organizations is needed for CE implementation in the CI. In this regard, identifying the extent to which these parties could contribute separately to the $\mathrm{CE}$ in the $\mathrm{CI}$ would be an interesting future research area. Fourth, there is also a necessity of doing future research on exploring the roadmap towards successful CE implementation in the CI with the collaborative influence from externals stakeholders of the construction supply chain. Finally, this study found that the government contribution to the CE differs from the geographic context. For instance, the Chinese government was prominent in planning a closed-loop economy to pursue robust economic development (Zink and Geyer, 2017; Munaro et al., 2020). Thus, the Chinese predominance of CE research is conceivable, and this has also affirmed through the SLR by Munaro et al. (2020). In this vein, conducting future research on lesson learned from countries with effective $\mathrm{CE}$ models would be a topical research direction. Despite these limitations and overlooked areas, this paper helps understand the government's role towards CE implementation in the CI while encouraging more SLRs around the domain under study.

\section{Conclusion}

This study aimed to explore the current role of the government that steers the CI towards a CE. To achieve this aim, a SLR was done using the PRISMA guideline, including 125 articles from four search systems from 20022020. The SLR was done with both descriptive and content analysis.

As for the descriptive analysis, the refined articles were analyzed based on their year of publication and geographical dispersion. Most articles (19) were published in the year 2019. Besides, China is the dominant country for publishing most of the articles on the area under study. Under content analysis, the study found that 
the government contribute to the $\mathrm{CE}$ in the $\mathrm{CI}$ by playing four roles of regulating, subsidizing, encouraging and informing. The implementation of $\mathrm{CE}$ in the $\mathrm{CI}$ is not a solitary effort. Instead, a collaborative effort from the government, government agencies, research institutions and non-government organizations should exist for the paradigm shift from a linear supply chain to a circular supply chain in the CI. After reviewing the literature, the study outlined future research directions to advance the understanding in the domain under study.

Even though several SLRs have been done on CE in the CI (Benachio et al., 2020; Munaro et al. 2020), all these reviews only provide a holistic understanding of it. Benachio et al. (2020) pointed out that the government has a crucial role in $\mathrm{CE}$ implementation in the CI; however, they have not comprehensively investigated the government's contribution towards CE. In this regard, the current review is framed around a completely different yet grossly disregarded concern: the role of government that steers the CI towards a CE. Herein, the current study contributes to the research by exploring an overlooked area in the existing literature and outlining plenty of future research avenues to expand this understudied area.

As practical implications, the study's findings established that through regulating, subsidizing, encouraging, and informing, the government contributes to the CE implementation in the CI. However, the government influence on $\mathrm{CE}$ varies with different geographical contexts. Therefore, this study indicates the measures that should be taken by governments of different countries with poor adoption of CE. The study found that the government alone could not be able to steer the CI towards the CE. Instead, a collaborative impetus from government, government agencies, research institutions and non-government organizations is required to implement $\mathrm{CE}$ in the CI successfully. This acknowledges all these parties that they have a significant role in transforming from liner to circular supply chain in the CI.

\section{References}

Adams, K.T., Osmani, M., Thorpe, T. and Thornback, J. (2017). Circular economy in construction: current awareness, challenges and enablers. In: Proceedings of the Institution of Civil Engineers-Waste and Resource Management, 170(1), 15-24. doi:10.1680/jwarm.16.00011

Ajayi, S.O. and Oyedele, L.O. (2017). Policy imperatives for diverting construction waste from landfill: Experts' recommendations for UK policy expansion. Journal of cleaner production, 147, 57-65. doi:10.1016/j.jclepro.2017.01.075

Akinade, O., Oyedele, L., Oyedele, A., Davila Delgado, J.M., Bilal, M., Akanbi, L., Ajayi, A. and Owolabi, H. (2020). Design for deconstruction using a circular economy approach: Barriers and strategies for improvement. Production Planning \& Control, 31(10), 829-840. doi 10.1080/09537287.2019.1695006

Ali, A., Mahfouz, A. and Arisha, A. (2017). Analyzing supply chain resilience: integrating the constructs in a concept mapping framework via a systematic literature review. Supply Chain Management: An International Journal, 22(1), 16-39. doi:10.1108/SCM-06-2016- 0197

Ali, A.K. (2019). Mapping a Resource-Based Design Workflow to Activate a Circular Economy in Building Design and Construction. IOP Conference Series: Earth and Environmental Science, 225. doi:10.1088/1755$1315 / 225 / 1 / 012010$

Banias, G., Achillas, C., Vlachokostas, C., Moussiopoulos, N. and Tarsenis, S. (2010). Assessing multiple criteria for the optimal location of a construction and demolition waste management facility. Building and environment, 45(10), 2317-2326. doi:10.1016/j.buildenv.2010.04.016

Begum, R.A., Siwar, C., Pereira, J.J. and Jaafar, A.H. (2006). A benefit-cost analysis on the economic feasibility of construction waste minimization: the case of Malaysia. Resources, conservation and recycling, 48(1), 86-98. doi:10.1016/j.resconrec.2006.01.004

Begum, R.A., Siwar, C., Pereira, J.J., and Jaafar, A.H.M. (2007). Implementation of waste management and minimization in the construction industry of Malaysia. Resources, Conservation and Recycling, 51(1), 190-202. doi:10.1016/j.resconrec.2006.09.004 
Benachio, G.L.F., Freitas, M.D.C.D. and Tavares, S.F. (2020). Circular economy in the construction industry: A systematic literature review. Journal of Cleaner Production, 260, 121046. doi:10.1016/j.jclepro.2020.121046

Boulding, K. (1966). The Economics of the Coming Spaceship Earth.

Calvo, N., Varela-Candamio, L. and Novo-Corti, I. (2014). A dynamic model for construction and demolition (C\&D) waste management in Spain: Driving policies based on economic incentives and tax penalties. Sustainability, 6(1), 416-435. doi: 10.3390/su6010416.

Chang, Y.T. and Hsieh, S.H. (2019). A Preliminary Case Study on Circular Economy in Taiwan's Construction. In IOP Conference Series: Earth and Environmental Science, 225(1), 012069.

Chileshe, N., Rameezdeen, R., Hosseini, M.R. and Lehmann, S. (2015). Barriers to implementing reverse logistics in South Australian construction organizations. Supply Chain Management: An International Journal, 20(2), 179204. doi: /10.1108/SCM-10-2014-0325

Chileshe, N., Rameezdeen, R., Hosseini, M.R., Lehmann, S. and Udeaja, C. (2016). Analysis of reverse logistics implementation practices by South Australian construction organizations. International Journal of Operations \& Production Management, 36(3), 332-56. doi:10.1108/IJOPM-01-2014-0024

Esa, M.R., Halog, A. and Rigamonti, L. (2017). Developing strategies for managing construction and demolition wastes in Malaysia based on the concept of circular economy. Journal of Material Cycles and Waste Management, 19(3), 1144-1154. doi:10.1007/s10163- 016-0516-x

Geissdoerfer, M., Savaget, P., Bocken, N.M. and Hultink, E.J. (2017). The Circular Economy-A new sustainability paradigm?. Journal of cleaner production, 143, 757-768. doi:10.1016/j.jclepro.2016.12.048

Ghisellini, P., Cialani, C. and Ulgiati, S. (2016). A review on circular economy: the expected transition to a balanced interplay of environmental and economic systems. Journal of Cleaner production, 114, 11-32. doi: 10.1016/j.jclepro.2015.09.007

Govindan, K. and Hasanagic, M. (2018). A systematic review on drivers, barriers, and practices towards circular economy: a supply chain perspective. International Journal of Production Research, 56(1-2), 278-311. doi: 10.1080/00207543.2017.1402141

Hao, J.L., Hills, M.J. and Tam, V.W. (2008). The effectiveness of Hong Kong's Construction Waste Disposal Charging Scheme. Waste Management \& Research, 26(6), 553-8. doi: 10.1177/0734242X07085345

Hao, J.L., Yang, J., Hills, M.J. and Huang, T. (2007). A simulation model using system dynamic method for construction and demolition waste management in Hong Kong. Construction Innovation, 7(1), 7-21. doi: $10.1108 / 14714170710721269$

Hao, J.L.J., Tam, V.W.Y., Yuan, H.P., Wang, J.Y. and Li, J.R. (2010). Dynamic modeling of construction and demolition waste management processes. Engineering, Construction and Architectural Management, 17(5), 47692. doi: 10.1108/09699981011074574

Hopkinson, P., De Angelis, R. and Zils, M. (2020). Systemic building blocks for creating and capturing value from circular economy. Resources, Conservation and Recycling, 155, 104672. doi: 10.1016/j.resconrec.2019.104672

Huang, B., Wang, X., Kua, H., Geng, Y., Bleischwitz, R. and Ren, J. (2018). Construction and demolition waste management in China through the 3R principle. Resources, Conservation and Recycling, 129, 36-44. doi: 10.1016/j.resconrec.2017.09.029

Jia, F., Yin, S., Chen, L. and Chen, X. (2020). Circular economy in textile and apparel industry: A systematic literature review. Journal of Cleaner Production, 120728. doi: 10.1016/j.jclepro.2020.120728

Li, J., Zuo, J., Guo, H., He, G. and Liu, H. (2018). Willingness to pay for higher construction waste landfill charge: A comparative study in Shenzhen and Qingdao, China. Waste Management, 81(Nov), 226-33. doi: 10.1016/j.wasman.2018.09.043

Mahpour, A. (2018). Prioritizing barriers to adopt circular economy in construction and demolition waste management. Resources, Conservation and Recycling, 134, 216-27. doi: 10.1016/j.resconrec.2018.01.026

Mália, M., de Brito, J., Pinheiro, M.D. and Bravo, M. (2013). Construction and demolition waste indicators. Waste Management \& Research, 31(3), 241-255. doi:10.1177/0734242X12471707 
Moher, D., Liberati, A., Tetzlaff, J. and Altman, D.G. (2009). Preferred reporting items for systematic reviews and meta-analyses: the PRISMA statement. Ann. Intern.Med, 151(4), 264e269. doi:10.7326/0003-4819-151-4200908180-00135.

Munaro, M.R., Tavares, S.F. and Bragança, L. (2020). Towards circular and more sustainable buildings: A systematic literature review on the circular economy in the built environment. Journal of Cleaner Production, 260, 121134. doi:10.1016/j.jclepro.2020.121134

Nasir, M.H.A., Genovese, A., Acquaye, A.A., Koh, S.C.L. and Yamoah, F. (2017). Comparing linear and circular supply chains: A case study from the construction industry. International Journal of Production Economics, 183, 443-457. doi: 10.1016/j.ijpe.2016.06.008.

Nunes, B.T., Pollard, S.J., Burgess, P.J., Ellis, G., De los Rios, I.C. and Charnley, F. (2018). University contributions to the circular economy: professing the hidden curriculum. Sustainability, 10(8), 2719. doi:10.3390/su10082719

Pomponi, F. and Moncaster, A. (2017). Circular economy for the built environment: A research framework. Journal of Cleaner Production, 143, 710-718. doi: 10.1016/j.jclepro.2016.12.055

Prajapati, H., Kant, R. and Shankar, R. (2019). Bequeath life to death: State-of-art review on reverse logistics. Journal of Cleaner Production, 211, 503-20. doi:10.1016/j.jclepro.2018.11.187

RMIT University (2021, May 07) “Library subject guides". Retrieved from https://rmit.libguides.com/c.php?g=724535\&p=5191552

Rodríguez, G., Medina, C., Alegre, F.J., Asensio, E., Sánchez de. and Rojas, M.I. (2015). Assessment of Construction and Demolition Waste plant management in Spain: in pursuit of sustainability and eco-efficiency. Journal of Cleaner Production, 90, 16-24. doi:10.1016/j.jclepro.2014.11.067

Schamne, A.N. and Nagalli, A. (2018). Evaluation of the potential application of the precepts of solid waste reverse logistics to the civil construction sector in Curitiba, Paraná. International Journal of Environment and Waste Management, 22(1-4), 24-47. doi:10.1504/IJEWM.2018.094102

Seuring, S. and Müller, M. (2008). From a literature review to a conceptual framework for sustainable supply chain management. Journal of Cleaner Production, 16(15), 1699-1710. doi: 10.1016/j.jclepro.2008.04.020.

Snyder, H. (2019). Literature review as a research methodology: An overview and guidelines. Journal of Business Research, 104, 333-339. doi:10.1016/j.jbusres.2019.07.039

Stahel, W.R. (2010). The Performance Economy. Palgrave Macmillan, Basingstoke, UK.

Stahel, W.R. and Reday-Mulvey, G. (1981). Jobs for tomorrow: the potential for substituting manpower for energy, 1. ed. ed. Vantage, New York, NY

Tam, V.W.Y. (2009). Comparing the implementation of concrete recycling in the Australian and Japanese construction industries. Journal of Cleaner Production, 17(7), 688-702. doi:10.1016/j.jclepro.2008.11.015

Tam, V.W.Y. (2009). Comparing the implementation of concrete recycling in the Australian and Japanese construction industries. Journal of Cleaner Production, 17(7), 688-702. doi: 10.1016/j.jclepro.2008.11.015

Tam, V.W.Y. and Tam, C.M. (2006). Evaluations of existing waste recycling methods: A Hong Kong study. Building and Environment, 41(12), 1649-60. doi:10.1016/j.buildenv.2005.06.017

Tranfield, D., Denyer, D. and Smart, P. (2003), Towards a methodology for developing evidence-informed management knowledge by means of systematic review. British Journal of Management, 14(3), 207-222. doi:10.1111/1467-8551.00375

Van Buren, N., Demmers, M., Van der Heijden, R. and Witlox, F. (2016). Towards a circular economy: The role of Dutch logistics industries and governments. Sustainability, 8(7), 647. doi:10.3390/su8070647

Wijewickrama, M.K.C.S., Chileshe, N., Rameezdeen, R. and Ochoa, J. J. (2020a) Best Practices for Diverting Demolition Waste from Landfill: A Systematic Literature Review In: Scott, L and Neilson, C J (Eds) Proceedings of the 36th Annual ARCOM Conference, 7-8 September 2020, UK, Association of Researchers in Construction Management, 675-684 
Wijewickrama, M.K.C.S., Chileshe, N., Rameezdeen, R. and Ochoa, J.J. (2021). Information Sharing in Reverse Logistics Supply Chain of Demolition Waste: A Systematic Literature Review. Journal of Cleaner Production, 124359. doi:10.1016/j.jclepro.2020.124359

Wijewickrama, M.K.C.S., Chileshe, N., Rameezdeen, R. and Ochoa, J.J. (2020b). Quality assurance in reverse logistics supply chain of demolition waste: A systematic literature review. Waste Management \& Research, 39(1), 3-24. doi:10.1177/0734242X20967717.

Wu, H., Duan, H., Zheng, L., Wang, J., Niu, Y. and Zhang, G. (2016). Demolition waste generation and recycling potentials in a rapidly developing flagship megacity of South China: Prospective scenarios and implications. Construction and Building Materials, 113, 1007-1016. doi:10.1016/j.conbuildmat.2016.03.130

Yu, A.T.W., Poon, C.S., Wong, A., Yip, R. and Jaillon, L. (2013). Impact of construction waste disposal charging scheme on work practices at construction sites in Hong Kong. Waste Management, 33(1), 138-146. doi:10.1016/j.wasman.2012.09.023

Yuan, H. (2017). Barriers and countermeasures for managing construction and demolition waste: A case of Shenzhen in China. Journal of Cleaner Production, 157, 84-93. doi:10.1016/j.jclepro.2017.04.137

Zanni, S., Simion, I.M., Gavrilescu, M. and Bonoli, A. (2018). Life cycle assessment applied to circular designed construction materials. Procedia CIRP, 69, 154-159. doi:10.1016/j.procir.2017.11.040

Zhao, W., Ren, H. and Rotter, V.S. (2011). A system dynamics model for evaluating the alternative of type in construction and demolition waste recycling center-The case of Chongqing, China. Resources, Conservation and Recycling, 55(11), 933-944. doi:10.1016/j.resconrec.2011.04.011

Zhu, Q., Sarkis, J. and Lai, K.H. (2018). Regulatory policy awareness and environmental supply chain cooperation in China: A regulatory-exchange-theoretic perspective. IEEE Transactions on Engineering Management, 65(1), 46-58. doi:10.1109/TEM.2017.2734940.

Zink, T. and Geyer, R. (2017). Circular economy rebound. Journal of Industrial Ecology, 21(3), 593-602. doi:10.1111/jiec. 12545 